Д'яченко Ю. Ю. [1; ORCID ID: 0000-0002-6580-8874], д.е.н., проф., завідувач кафедри міжнародної економіки і туризму

${ }^{1}$ Східноукраїнський національний університет імені Володимира Даля, м. Сєвєродонецьк

\title{
ІНФОРМАЦІЙНО-КОМУНІКАЦІЙНІ ТЕХНОЛОГІЇ ЯК ЧИННИК СТАЛОГО РОЗВИТКУ ОСВІТНІХ ІНСТИТУЦІЙ В ЕКОНОМІЦІ ЗНАНЬ
}

Дослідження спрямоване на виявлення передумов забезпечення якісної освіти та заохочення можливостей навчання протягом усього життя, необхідних в умовах економіки знань. У статті розглянуті можливості застосування інформаційно-комунікаційних технологій для навчання студентів та розвитку людських ресурсів. Розглянуто використання інформаційно-комунікаційних технологій та дистанційного навчання в освіті. Зазначено, що інформаційно-комунікаційні технології надають можливість врахувати когнітивні характеристики кожного студента з метою запровадження індивідуального підходу до навчання.

Ключові слова: економіка знань; інформаційно-комунікаційні технології; сталий розвиток; освітня інституція, ринок освітніх послуг.

Постановка проблеми. Однією з Цілей сталого розвитку ООН забезпечення всеосяжної та справедливої якісної освіти та сприяння можливостям навчання протягом усього життя [1]. Одним 3 шляхів досягнення цієї мети $€$ розширення можливостей навчання за допомогою технологій, що забезпечують підтримку прийняття рішень в управлінні навчанням та освітою. У цих рамках ми розглядаємо можливість та умови застосування інформаційно-комунікаційних технологій у навчанні студентів та розвитку людських ресурсів. Для вирішення цього питання ми маємо враховувати особливості поведінки людини на базі системного та когнітивного підходів.

Аналіз досліджень і публікацій. Один з найбільш загальних підходів до опису людської поведінки - це теорія систем Лумана. На думку Лумана, те, що відрізняє систему та навколишнє середовище, ix суперечності, $\epsilon$ центральним у існуванні систем із власною поведінкою [2]. Відповідно, фундаментальними передумовами людської поведінки з точки зору системної теорії $€$ самосвідомість як форма внутрішнього зворотного зв'язку та спілкування як форма взаємодії із зовнішнім середовищем. Луман вважав, що непередбачуваність поведінки системи досягається завдяки 
взаємодії: «спілкування - це елементарна одиниця самоконституції; дія $€$ елементарною одиницею самоспостереження та самоопису соціальної системи» [2]. Ці акти непередбачуваного спілкування, комунікації, $є$ прерогативою людської поведінки.

Виділення невирішених раніше питань. Забезпечення та управління комунікаціями $\epsilon$ предметною областю традиційних інформаційно-комунікаційних технологій. Але розвиток науки та техніки приводить до створення нелюдських акторів з інтелектом, який можна було б розвинути рамках підходу когнітивної науки як міждисциплінарного поля, що охоплює філософію, психологію, штучний інтелект, нейронауку, лінгвістику та антропологію. Такі когнітивні агенти (чат-боти, системи підтримки прийняття рішень) як «підсилювачі» людських когнітивних здібностей вже зараз підвищують ефективність функціонування економіки знань, в якій рушійною силою прогресу $€$ знання, зосереджені в людському капіталі. Усталеної теорії взаємодії людських та програмноапаратних акторів поки що немає. Але вже сьогодні ми маємо готувати майбутніх фахівців до роботи в умовах такої взаємодії.

Постановка завдання. Важливим аспектом підготовки до такої взаємодії $€$ створення та опанування в процесі навчання певних моделей реальності через освіту, яка формує необхідні навички та вміння. Розглянемо вимоги до цих навичок та вмінь, які мають бути сформовані у закладах вищої освіти.

Основний матеріал дослідження. Вища освіта сьогодні стикається з певними проблемами, такими як висока конкуренція на ринку освітніх послуг, зростаючі ризики, відсутність передбачуваності. Управління освітою як послугою - це процес, спрямований на вдосконалення структури постачальників освітніх послуг та освітньої структури суспільства. Для побудови цієї структури нам потрібно розглянути дії, що стосуються певної системи та забезпечення ії стійкого розвитку. Реалізація таких дій вимагає управління через встановлення стратегії та координацію зусиль. Для досягнення цілей нам потрібно мати певну передбачуваність системи. Але через непередбачуваність поведінки людини ми все одно будемо стикатися з певною невизначеністю у майбутньому. Це унеможливлює побудову закритої системи, яка могла б надати можливість отримати заздалегідь визначені результати інтелектуальної діяльності (включаючи штучний інтелект). І це стає джерелом нестабільності та потенційної небезпеки.

3 іншого боку, наступному поколінню випаде доля боротись із змінами клімату, пандеміями та іншими глобальними проблемами, 
які мають складний характер та можуть бути вирішені на базі системного підходу.

Зростаюча інтенсивність комунікацій, збільшення долі часу, який працівники проводять із комп'ютерними пристроями, вимагають поглиблення загальних навичок та вмінь комунікації.

Для цього потрібно формування широкого кругозору. Традиційний підхід до освіти, яка дає глибокі вузькі знання (hard skills) й готує до однієї роботи на все життя, має змінитись.

Тому ми маємо передбачити будь-які майбутні зміни на робочому місці при передачі знань студентам, формуванні їх вмінь та навичок. Одним з шляхів до цієї мети є введення до навчальних планів підготовки студентів-економістів дисциплін «Управління інформацією», «нтелектуальні технології в корпоративному управлінні», «Інноваційний розвиток підприємства та економіка знань», «Когнітивні технології в економіці» [3].

Також ми маємо визначити, якою мірою мають враховуватись в індивідуальній освітній траєкторії студента його навчальні досягнення поза університетом (МОOС на кшталт Coursera та Prometheus, кваліфікаційні сертифікати тощо). Масові онлайн-курси, які дають змогу долучитись до викладання кращих у світі професорів, не стали панацеєю: їх успішно завершують лише проценти від тих, хто починав. Можливо, не вистачає правильної мотивації та живого спілкування? I чи не має ті ж вади дистанційна освіта?

Швидке зростання галузі дистанційної освіти ставить старі питання щодо ефективності освіти та мотивації її здобувачів, а також приносить прискореними темпами широкий спектр нових проблем. Інформаційно-комунікаційна глобалізація зі свого боку збільшує потребу у створенні науково обґрунтованої стратегії розвитку дистанційної освіти. І однією з головних цілей цієї стратегії має бути підтримка високої якості освіти на всіх етапах навчання.

Одним 3 інструментів вирішення цих проблем $є$ системи управління навчанням. Сьогодні ці системи дають змогу розірвати просторово-часовий зв'язок між викладачем та студентом. Одна 3 найпоширеніших - Moodle як безкоштовна та відкрита програма для управління навчальним програмним забезпеченням, яка використовується для створення приватних вебсайтів 3 онлайнкурсами для вчителів та слухачів з метою досягнення навчальних цілей. Важливою умовою ефективного функціонування систем управління навчанням $€$ розвиток внутрішньоуніверситетських 
інформаційних та комунікаційних мереж, в тому числі з залученням сучасних технологій штучного інтелекту.

Агенти зі штучним інтелектом [4] як посередники між студентами та системою управління навчанням можуть частково замінити дві основні форми роботи викладачів: створення навчальних матеріалів та перевірку знання студентів. Рішення першого завдання означає автоматизацію розробки контенту для онлайн-курсів шляхом фільтрації неструктурованих джерел у лекції та вправи. Друге завдання - це ведення діалогу, в рамках якого створюються завдання для студентів, аналізуються їхні відповіді та оцінюється рівень знань студентів.

3 точки зору інформаційно-комунікаційних технологій, в цій діяльності наявні такі проблеми: ведення діалогу природною мовою, класифікація природної мови та аналіз тексту. Використання інформаційно-комунікаційних технологій також має бути інтегровано 3 аудіовізуальною інформацією, представленою у вигляді анімації, відеофільмів, презентацій, текстової та графічної інформації за допомогою інтерактивного діалогу.

Найбільшою перевагою інформаційно-комунікаційних технологій $€$ можливість застосування індивідуального підходу до студентів, що дає їм можливість вивчати навчальний матеріал в індивідуальному темпі та послідовності, що враховує психологічні особливості кожного учня та значно покращує якість засвоєння навчального матеріалу. Персоналізація інформації має великий вплив на ефективність навчання як студентів, так і працівників організації або підприємства [5]:

- інтелект, інтегрований у системі освіти, передбачає відповідне навчання, яке базується на аналізі та статистиці відповідно до рівня того, хто навчається;

- кожен здобувач освіти отримає персонального тренера, який навчатиметься та краще працює;

- додаються можливості машинного навчання з метою розвитку талантів та вдосконалення стратегій управління :

- штучний інтелект може автоматизовувати роботу з рутинними завданнями;

- системи штучного інтелекту пропонують програми розвитку та для забезпечення кращої якості роботи.

Технології штучного інтелекту дають змогу оперативно аналізувати (очищувати, досліджувати та робити висновки) дані тими працівниками, які не мають спеціальних навичок аналізу даних. Кінцева мета системи підтримки навчання - зробити так, щоб 
знання, вміння та досвід персоналу відповідали як стратегії підприємства чи організації так і вимогам до працівника чи студента [6].

Висновки. Розглядаючи дистанційне навчання в освіті, технології розвитку людських ресурсів та інформаційнокомунікаційні технології в освіті, можна зазначити, що найбільша перевага інформаційно-комунікаційних технологій - це можливість використання індивідуального підходу до здобувачів освіти, що дає враховувати їх психологічні особливості, що значно покращує якість оволодіння навчальним матеріалом, підвищує загальну ефективність навчання. Для підготовки до змін у середовищі ведення бізнесу, технологічному рівні виробництва ми пропонуємо оновлення освітніх програм з акцентом на інформаційно-комунікаційні технології.

1. Перетворення нашого світу: Порядок денний в області сталого розвитку на період до 2030 року : резолюція A/RES/70/1, схвалена Генеральною Асамблеєю $\mathrm{OOH} 25$ вересня 2015 p. URL: https://documents-ddsny.un.org/doc/UNDOC/GEN/N15/291/92/PDF/N1529192.pdf?OpenElement (дата звернення: 22.05.2020). 2. Луман Н. Социальные системы. Очерк общей теории / перевод с немецкого И. Д. Газиева ; под редакцией Н. А. Головина. СПб. : Наука, 2007. 641 c. 3. Nenkov N., Petrova M., Dyachenko Y. Bondarenko G., Pustovit V. Intelligent and Cognitive Technologies in Education of International Economic Relations Students and Human Resource Development: Methodology in Language Teaching and Distance Learning. European Journal of Sustainable Development. 2017. Vol.6, No. 4. P. 353-360. 4. Petrova M., Buzkol., Dyachenko Y. Cognitive, intelligence technologies and economic foundations of teaching of international economic relations and tourism. Engineering for rural development : 17th International Scientific Conference : Proceedings. Vol. 17, May 23-25, 2018. Jelgava, Latvia. Pp. 1102-1106. 5. Artificial Intelligence Enables Proficiency: вебсайт. URL: https://chatbotslife.com/artificial-intelligence-enables-proficiency-44150873011c (дата звернення: 22.05.2020). 6. Petrova M., Minchev N., Dyachenko Y. Modern Information Technologies As An Opportunity For Development And Integration Of Innovative Small And Medium Enterprises In Clusters. International Balkan and Near Eastern Social Sciences Conference Series : Proceedings of IBANESS Conference Series, March 12-13, 2016. Plovdiv, Bulgaria: University of Agribusiness and Rural Development, 2016. Pp. 499-505.

\section{REFERENCES:}

1. Peretvorennia nashoho svitu: Poriadok dennyi v oblasti staloho rozvytku na period do 2030 roku : rezoliutsiia A/RES/70/1, skhvalena Heneralnoiu Asambleieiu OON 25 veresnia $2015 \quad$ r. $\quad$ URL: https://documents-ddsny.un.org/doc/UNDOC/GEN/N15/291/92/PDF/N1529192.pdf?OpenElement (data zvernennia: 22.05.2020). 2. Luman N. Sotsialnyie sistemyi. Ocherk obschey teorii / perevod s nemetskogo I. D. Gazieva; pod redaktsiey N. A. Golovina. SPb. : Nauka, 2007. 641 c. 3. Nenkov N., Petrova M., Dyachenko Y. Bondarenko G., Pustovit V. Intelligent and Cognitive Technologies in Education of International Economic Relations Students and 
Human Resource Development: Methodology in Language Teaching and Distance Learning. European Journal of Sustainable Development. 2017. Vol. 6, No. 4. Pp. 353360. 4. Petrova M., Buzko I., Dyachenko Y. Cognitive, intelligence technologies and economic foundations of teaching of international economic relations and tourism. Engineering for rural development : 17th International Scientific Conference : Proceedings. Vol. 17, May 23-25, 2018. Jelgava, Latvia. Pp. 1102-1106. 5. Artificial Intelligence Enables Proficiency : vebsait. URL: https://chatbotslife.com/artificialintelligence-enables-proficiency-44150873011c (data zvernennia: 22.05.2020). 6. Petrova M., Minchev N., Dyachenko Y. Modern Information Technologies As An Opportunity For Development And Integration Of Innovative Small And Medium Enterprises In Clusters. International Balkan and Near Eastern Social Sciences Conference Series: Proceedings of IBANESS Conference Series, March 12-13, 2016. Plovdiv, Bulgaria : University of Agribusiness and Rural Development, 2016. Pp. 499505.

Diachenko Y. Y. ${ }^{[1 ; 0 R C I D ~ I D ~: ~ 0000-0002-6580-8874], ~}$

Doctor of Economics, Professor, Head of International Economics and Tourism Department

${ }^{1}$ Volodymyr Dahl East Ukrainian National University, Severodonetsk

\section{INFORMATION AND COMMUNICATION TECHNOLOGIES AS A FACTOR OF SUSTAINABLE DEVELOPMENT OF EDUCATIONAL INSTITUTIONS IN THE KNOWLEDGE ECONOMY}

The study aims to identify the prerequisites for ensuring education quality and encouraging lifelong learning opportunities needed in a knowledge economy. The article considers the possibilities of using information and communication technologies for student learning and human resources development. Also, we consider the connection between information and communication technologies and distance learning.

The traditional approach to education, which provides hard skills and prepares for one job in life, needs to change. Therefore, we must anticipate any future changes in the workplace during the transfer of knowledge to students, the formation of their skills and abilities. An important aspect of preparation for the interaction of human and software-hardware actors is the creation and mastery in the process of learning certain models of reality through education, which forms the necessary skills and abilities. One of the ways to this goal is the introduction of disciplines in the subject area of information and communication technologies in the economics curricula.

Considering distance learning in education, human resource development technologies and information and communication technologies in education, we can say that the biggest advantage of information and communication technologies is the ability to use an individual approach to students, which allows taking into account their psychological characteristics, which significantly improves the quality of learning material 
and increases the overall effectiveness of education. To prepare for changes in the business environment, the technological level of production, we offer updates to educational programs with an emphasis on information and communication technologies.

Keywords: knowledge economy; information and communication technologies; sustainability; educational institution; market of educational services.

Дьяченко Ю. Ю. [1; ORCID ID : 0000-0002-6580-8874], д.э.н., профессор, заведующий кафедрой международной экономики и туризма

${ }^{1}$ Восточноукраинский национальный университет имени Владимира Даля, г. Северодонецк

\title{
ИНФОРМАЦИОННО-КОММУНИКАЦИОННЫЕ ТЕХНОЛОГИИ КАК ФАКТОР УСТОЙЧИВОГО РАЗВИТИЯ ОБРАЗОВАТЕЛЬНЫХ ИНСТИТУЦИЙ В ЭКОНОМИКЕ ЗНАНИЙ
}

\begin{abstract}
Исследование направлено на выявление предпосылок обеспечения качественного образования и поощрения возможностей обучения В течение всей жизни, необходимых в условиях экономики знаний. В статье рассмотрены возможности применения информационнокоммуникационных технологий для развития человеческих ресурсов и обучения студентов. Рассмотрено использование информационнокоммуникационных технологий и дистанционного обучения В образовании. Указано, что информационно-коммуникационные технологии предоставляют возможность учесть когнитивные характеристики каждого студента с целью внедрения индивидуального подхода к обучению.

Ключевые слова: экономика знаний; информационнокоммуникационные технологии; устойчивое развитие; образовательная организация; рынок образовательных услуг.
\end{abstract}

Стаття надійшла до редакції 25.06.2020 р. 